\title{
Peptides and Glycopeptides with Anti-Acetylcholinesterase Activity Obtained from Yeast Mannoproteins
}

\author{
Spontón Pablo ${ }^{1,2, *}$, Landoni Malena ${ }^{3}$, Couto Alicia $^{3}$, Tonarelli Georgina ${ }^{2}$, Simonetta Arturo ${ }^{1}$ \\ ${ }^{1}$ Department of Food Technology and Biotechnology, Laboratory of Microbiology and Biotechnology, School of Chemical Engineering, \\ National University of the Litoral, Santa Fe, Argentina \\ ${ }^{2}$ Department of Organic Chemistry, Bioactive Peptide Laboratory, School of Biochemistry and Biological Sciences, National University of \\ the Litoral, Santa Fe, Argentina \\ ${ }^{3}$ Center of Investigations in Hydrates of Carbon, National Council of Scientific and Technical Investigations, University of Buenos Aires, \\ Buenos Aires, Argentina
}

\section{Email address:}

pgsponton@gmail.com (S. Pablo), male22_rr@hotmail.com (L. Malena), acouto@qo.fcen.uba.ar (C. Alicia), tonareli@fbcb.unl.edu.ar (T. Georgina), asimonet@fiq.unl.edu.ar (S. Arturo)

${ }^{*}$ Corresponding author

\section{To cite this article:}

Spontón Pablo, Landoni Malena, Couto Alicia, Tonarelli Georgina, Simonetta Arturo. Peptides and Glycopeptides with AntiAcetylcholinesterase Activity Obtained from Yeast Mannoproteins. International Journal of Microbiology and Biotechnology. Vol. 3, No. 3, 2018, pp. 62-70. doi: 10.11648/j.ijmb.20180303.11

Received: June 27, 2018; Accepted: August 6, 2018; Published: October 12, 2018

\begin{abstract}
Purified mannoproteins from 5 yeast strains belonging to the genera Brettanomyces, Candida, Pichia and Saccharomyces were studied. Each mannoprotein extract was hydrolysed with proteolytic enzymes, generating small peptides whose inhibitory activity against acetylcholinesterase (AChE) was determined. Partial purification of six selected mannoprotein extracts was done by reversed phase chromatography, six fractions with relevant inhibitory activity being obtained. Chromatographic and spectroscopic analyses revealed mainly hydrophilic peptides, with molecular weight between 700 and $4800 \mathrm{Da}$. The presence of sugars in all fractions was determined, mannose being the most abundant one. Subsequently, the most active fractions were again separated by affinity chromatography, which led to two new types of fractions: peptidic fractions (PFs) and glycopeptidic fractions (GPFs). Results showed that all fractions inhibited AChE, although GPFs inhibited $\mathrm{AChE}$ to a greater degree than PFs, with a percentage of inhibition ranging from 49.3 to $77.8 \%$. Likewise, all GPFs fractions had higher values of inhibition than the corresponding whole fraction, while PFs showed lower percentages of antiacetylcholinesterase activity. These results suggest that glycopeptidic are the most interesting fractions for their ability to inhibit this enzyme. As a conclusion, it was shown that some peptides produced by hydrolysis of mannoproteins proved able to inhibit AChE and should be considered as potential anti-AChE agents and significant to the manufacturing of food with potential functional properties.
\end{abstract}

Keywords: Mannoproteins, Peptides, Glycopeptides, Acetylcholinesterase, Functional Foods

\section{Introduction}

Currently, it is assumed that food, in addition to acting as nutrients, can provide both bioactive compounds and health benefits to the human body, as well as reduce the risk of suffering from certain diseases. Research carried out in the design and elaboration of functional foods has devoted special attention to the study of the physiological role of dietary proteins. Bioactive peptides encoded in the protein structures are usually generated in vivo by the action of gastrointestinal enzymes, or they can also be obtained in vitro with specific enzymes, and/or produced during the biotechnological processes for the preparation of certain foods. These peptides have a broad biological activity such as antibacterial [1, 2], antifungal [3], antiviral [4], anticancer, antioxidant, and so on.

Dementia is a clinical syndrome caused by disorders that affect the brain [5,6], Alzheimer's disease (AD) being the most common type of dementia [7, 8]. AD, a neurological disorder that causes the death of nerve cells in the brain, is 
manifested in the deterioration of cognitive abilities and behavioral problems. In its advanced stages, AD leads to dementia and finally to death. In developed countries, it is one of the most important causes of death, after cardiovascular diseases and cancer. However, what makes this dementia have such a strong impact on the health system and society as a whole is its irreversible nature, the lack of curative treatment and the burden it represents for the family of those affected [9]. Although the factors of initiation that sustain this pathology remain to be elucidated, it is well established that $\mathrm{AD}$ is associated with a reduction in $\mathrm{ACh}$ levels [10]. This substance is the major neurotransmitter in the central nervous system through the action of the enzyme acetylcholinesterase (AChE), regulating nerve impulse transmission in the cholinergic synapse [11]. Therefore, one of the treatments used for $\mathrm{AD}$ is anti-acetylcholinesterase drugs that have an inhibitory action against AChE. Recent studies have shown that AChE inhibitors alleviate neuropsychiatric symptoms and provide beneficial effects on cognitive ability by increasing the levels of ACh within the synaptic region [12]. The inhibition of AChE also serves as a strategy for the treatment of other neurological disorders such as senile dementia, ataxia, myasthenia gravis and Parkinson's disease [13]. In this field, research has achieved the greatest therapeutic advances in the treatment of $\mathrm{AD}$ by inhibiting $\mathrm{AChE}$ and therefore improving both the patient behavior and his quality of life [10]. Some drugs, such as donepezil, rivastigmine and galantamine, proved effective in the treatment, though they have several side effects: gastrointestinal alterations, anorexia and heart rhythm disorders [14]. Currently the search for other inhibitors of this enzyme has intensified markedly. Some AChE inhibitor compounds have been found from various natural sources [15-18]. This opens a very little explored path, related to the study of anticholinesterastic properties of natural products.

Mannoproteins are proteins bound to sugar molecules (glycoproteins), specifically mannose residues, in a proportion ranging between $50-90 \%$. As a component of the cell wall of yeasts, they have been most studied in recent years. However, despite they are readily available, inexpensive and with numerous properties, compounds remain little used in the food industry. In addition, there are several foods naturally containing mannoproteins from yeast wall and ingested therewith naturally, therefore being a group of GRAS (generally regarded as safe) compounds [19]. Potential technological and industrial applications of yeast mannoproteins include control of pathogens in meat and poultry industry, increased immune response, improvements in digestion and absorption of nutrients in animals intended for human consumption, as well as enhancement of various wine organoleptic characteristics and different oenological procedures. In addition, it was observed that mannoproteins may have functional attributes for human consumption, which could contribute to increasing quality and food safety and thus consumer welfare.

This research article intends to continue with the study, fractionation and characterization of 6 mannoprotein hydrolysates from five yeast strains previously isolated from food products from Santa $\mathrm{Fe}$ and Patagonia regions (Argentina) that presented considerable inhibitory in vitro activity against AChE [20]. These peptides/glycopeptides could not only provide new therapeutic agents but also prevent the onset of the disease if incorporated with functional foods containing them.

\section{Material and Methods}

\subsection{Yeast Strains}

Saccharomyces cerevisiae DBFIQ L2, Pichia anomala LTW6, Candida blankii LTW7, Candida famata DBFIQ L17 and Brettanomyces intermedius DBFIQ L12, isolated from dairy products of the Santa $\mathrm{Fe}$ and Patagonia regions (Argentina), were obtained from the own collection of Dto. de Tecnología de Alimentos y Biotecnología (FIQ-UNL, Argentina). These strains were taxonomically identified by matrix-assisted laser desorption/ionization time-of-flight mass spectrometry (MALDI-TOF MS) using an LTQOrbitrap Veils Mass Spectrometer (Thermo Scientific, USA) and stored by cryopreservation at $-80{ }^{\circ} \mathrm{C}$. The strains were then activated for use by successive inoculations in malt extract - yeast extract broth (YM broth) (malt extract: $3 \mathrm{~g}$; yeast extract: $3 \mathrm{~g}$; tryptone: $5 \mathrm{~g}$; dextrose: $10 \mathrm{~g}$; distilled water: $1000 \mathrm{~mL}$ ), incubated at $30^{\circ} \mathrm{C}$ for periods of $48 \mathrm{~h}$, with stirring.

\subsection{Mannoprotein Extract}

Mannoproteins were obtained by heat extraction according to the method of [21] modified by [22]. Subsequently they were purified by Affinity Chromatography employing Concanavalin A and by dialysis [20].

\subsection{Enzymatic Digestion of Mannoproteins}

Enzymatic hydrolysis of each mannoprotein extract was first conducted with trypsin (E. C.: 3.4.21.4), pepsin (E. C.: 3.4.23.1) or proteinase K (E. C.: 3.4.21.64). In addition, each of these hydrolysated extracts was treated with chymotrypsin (E. C.: 3.4.21.1) as described by [20]. All enzymes were supplied by Sigma Chemical Co. (St. Louis, MO, USA).

\subsection{Acetylcholinesterase (AChE) Inhibitory Activity}

A microplate assay using the spectrophotometric method described by [23] with some modifications [24] was employed for the determination of the acetylcholinesterase inhibitory activity of the extracts. In this assay, $50 \mu \mathrm{L}$ of each sample was incubated with $50 \mu \mathrm{L}$ of $\operatorname{AChE}\left(0.25 \mathrm{U} \mathrm{mL}^{-1}\right)$ in a 96-well microplate for $30 \mathrm{~min}$ at room temperature. Subsequently, $100 \mu \mathrm{L}$ of the substrate solution [5,5'-

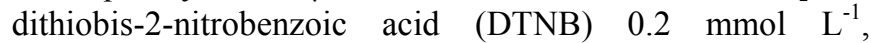
acetylthiocholine iodide $0.24 \mathrm{mmol} \mathrm{L} \mathrm{md}^{-1}$ and $\mathrm{Na}_{2} \mathrm{HPO}_{4} 0.04$ mmol L ${ }^{-1}, \mathrm{pH}$ 7.5] was added. The absorbance was read in an ELISA detector (Multiskan EX, Version 1.1, LabSystems, Helsinki, Finland) at $405 \mathrm{~nm}$ after $5 \mathrm{~min}$. Galantamine 
solution $\left(200 \mu \mathrm{mol} \mathrm{L} \mathrm{L}^{-1}\right)$ and phosphate buffer $\mathrm{pH} 7.5$ were respectively used as positive inhibition control and basal activity control of the enzyme. All of the reagents employed in this methodology were supplied by Sigma Co. (USA).

The percent inhibition produced by each extract was calculated as follows:

$$
\% I=100-\frac{E-B}{C-B} \times 100
$$

E: sample reading; C: control reading; B: white reading.

These assays were performed in triplicate. Results were reported as the average of the individual values.

\subsection{Reversed-Phase Liquid Chromatography Using Sep-Pak C18 Plus Tandem Cartridges}

A first fractionation of the most active mannoprotein extracts against AChE was performed by reversed phase liquid chromatography. To carry out this fractionation, tandem coupled Sep-Pak C18 Plus (WAT023501, Waters, USA) short cartridges were equilibrated with $2 \%(\mathrm{v} / \mathrm{v})$ acetonitrile (Merck, Darmstadt, Germany) (ACN) containing $0.1 \%(\mathrm{v} / \mathrm{v})$ trifluoroacetic acid (PanReac AppliChem, USA) (TFA). Each mannoprotein extract was dissolved in $2 \%(\mathrm{v} / \mathrm{v})$ ACN containing $0.1 \%(\mathrm{v} / \mathrm{v}) \mathrm{TFA}$ at a concentration of $2 \mathrm{mg}$ $\mathrm{ml}^{-1}$. The flow rate was $1 \mathrm{ml} \mathrm{min}^{-1}$, which remained constant throughout the experiment. It was equilibrated with $2 \%(\mathrm{v} / \mathrm{v})$ ACN containing $0.1 \%(\mathrm{v} / \mathrm{v})$ TFA (10 column volumes), the peptides being eluted with different ACN concentrations: 15, 30 and $75 \%(\mathrm{v} / \mathrm{v})$ containing $0.1 \%$ TFA (v/v). Five column volumes of each mixture were passed. Absorbance at $220 \mathrm{~nm}$ was measured using a Metrolab 1700 spectrophotometer (Buenos Aires, Argentina). The collected sample volumes were concentrated and lyophilized.

The chromatographic separation was done using an Econo Gradient peristaltic pump from Bio-Rad (Bio-Rad Laboratories, Inc. Hercules, CA, USA) and fractions were collected using a 2110 Bio-Rad Fraction Collector.

\subsection{High Performance Liquid Chromatography (HPLC)}

Fractions obtained from the most active mannoprotein extracts against AChE were analyzed by reversed phase HPLC Waters 1525 (USA). Waters (USA) and Beckman (CA, USA) analytical columns of C18 $(5 \mu \mathrm{m}, 4.6 \mathrm{~mm}$ x 260 $\mathrm{mm})$, as well as a two solvent system, were employed: Solvent A: 0.1\% (v/v) TFA in water; Solvent B: $0.08 \%(\mathrm{v} / \mathrm{v})$ TFA in ACN. Running time: 20 min; Gradient 5-50\% ACN; UV detection at $280 \mathrm{~nm}$.

\subsection{Analysis by MALDI-TOF}

Mass spectrometric data were obtained using a MALDITOF-TOF spectrometer (Ultraflex II Bruker Daltonics GmbsH, Bremen, Germany), in the CEQUIBIEM mass spectrometry facility (UBA, Buenos Aires, Argentina). The mass range investigated was up to $6 \mathrm{kDa}$.

\subsection{Analysis by High Performance Anion Exchange Chromatography with Pulsed Amperometric Detection (HPAEC-PAD)}

Samples were hydrolysed with 2 mol L ${ }^{-1}$ TFA for 2 hours at $100{ }^{\circ} \mathrm{C}$. The acid was removed by evaporation and the hydrolysate was brought to dryness and resuspended in water to be analyzed by HPAEC-PAD.

Sugar analysis was performed on a DX-500 Dionex BioLC system (Dionex Corporation, CA, USA) equipped with a pulse amperometric detector (PAD) for the detection of sugars using an $\mathrm{AgCl}$ reference electrode and an Au working electrode [25]. A Carbopack P-20 (Dionex Co., USA) column equipped with a pre-P-20 column was used for the analysis of monosaccharides. The injection volume for each analysis was $20 \mu \mathrm{L}$., with an isocratic elution with $\mathrm{NaOH} 16$ $\mathrm{mmol} \mathrm{L}^{-1}$ and a flow of $0.5 \mathrm{~mL} \mathrm{~min}^{-1}$.

These analyses were carried out in the Center for Research on Carbohydrates [(CIHIDECAR), CONICET-UBA, Buenos Aires, Argentina].

\subsection{Chromatographic Separation of the Most Active Fractions Against AChE and Determination of the Inhibitory Activity}

The most active mannoprotein fractions against AChE obtained by reversed phase chromatography were separated by affinity chromatography using Concanavalin A (GE Healthcore Bio-Sciencies AB, Uppsala, Sweden) as described by [20], obtaining two new fractions: a peptide fraction (PF) and a glycopeptide fraction (GPF). The inhibitory activity against AChE of each fraction was again determined as described above.

\subsection{Statistical Analysis}

All experiments were performed in triplicate. Values were reported as mean \pm standard deviation. Statistically significant differences among means of experimental design were studied by analysis of variance (ANOVA) at $\mathrm{P} \leq 0.05$.

\section{Results and Discussion}

In a previous research work [20], a wide range of inhibitory activity against AChE in the hydrolysed mannoprotein extracts was observed. The maximum inhibition value detected was $59 \%$ and corresponded to the extract of $C$. blankii LTW7 hydrolysed with pepsin/chymotrypsin. Other active extracts were the following ones: those of C. blankii LTW7 hydrolysed with trypsin (42.6\%), trypsin/chymotrypsin (39.3\%) and pepsin/chymotrypsin (59\%); those of S. cerevisiae DBFIQ L2 hydrolysed with proteinase $\mathrm{K}$ (54.4\%) and pepsin/chymotrypsin (46.4\%); and that of $P$. anomala LTW6 hydrolysed with pepsin/chymotrypsin $(41.1 \%)$. In the same research work, Inhibitory Concentration 50 (IC50) was determined for each sample, the extract of $S$. cerevisiae DBFIQ L2 hydrolysed with pepsin and chymotrypsin showing the lowest IC50 value against AChE $\left(6.8 \mathrm{mg} \mathrm{mL}^{-1}\right)$. 


\subsection{Reversed-Phase Liquid Chromatography}

Fractionation of the 6 previously selected mannoprotein extracts [20] by reversed-phase chromatography using different percentages of ACN resulted in 6 new fractions with significant inhibitory activity against AChE. Figure 1 shows the results of AChE inhibitory activity of these 6 fractions.
It can be seen that nearly all the fractions separated with $15 \%$ of $\mathrm{ACN}$, and the fraction obtained with $2 \%$ of $\mathrm{ACN}$ from $P$ anomala LTW6 hydrolysed with pepsin/chymotrypsin had the highest values of inhibition. The extracts of $C$. blankii LTW7 hydrolysed with trypsin and with pepsin/chymotrypsin, showed the highest values of activity ( $64 \%$ of inhibition).

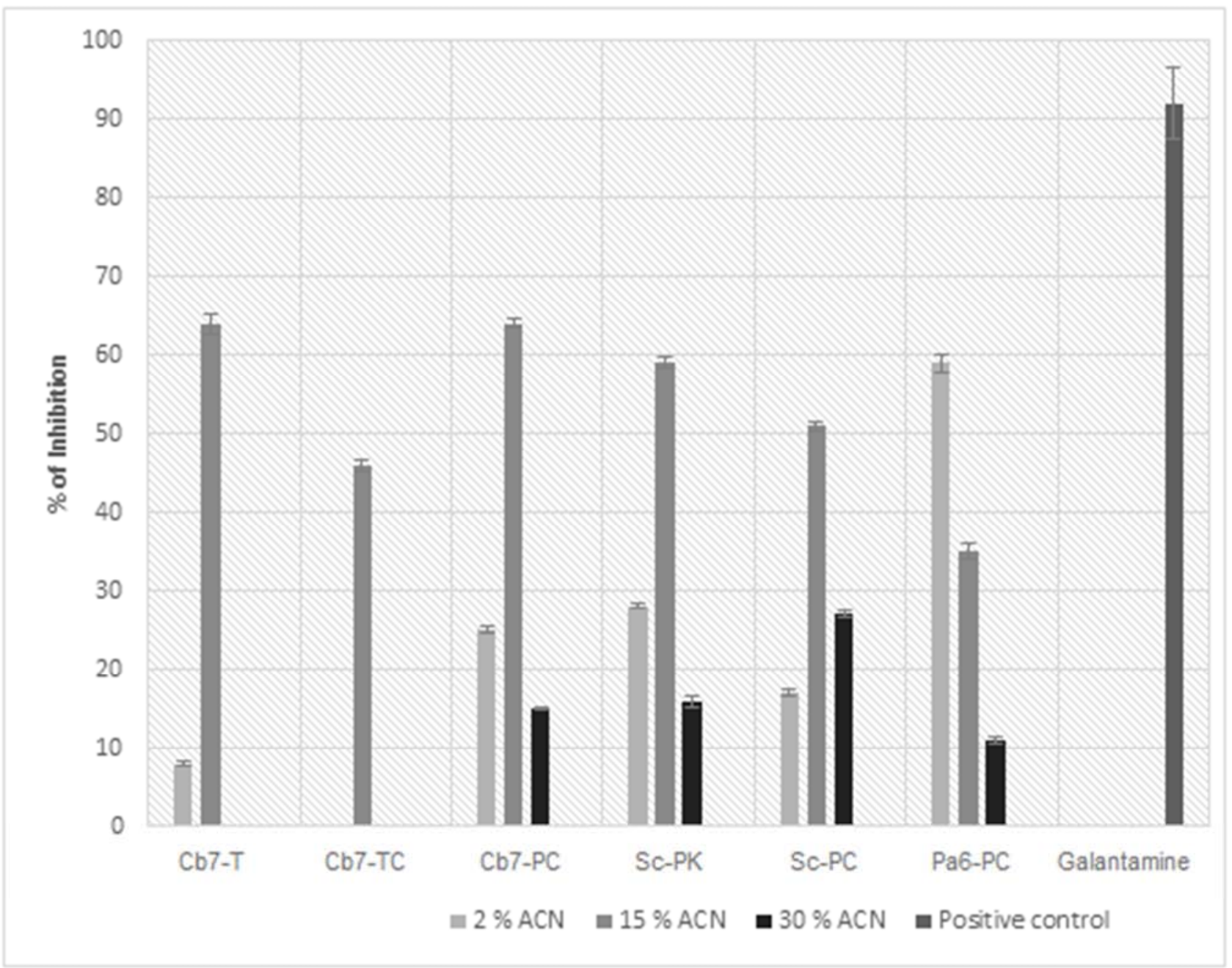

Figure 1. Inhibitory activity against AChE of the fractions obtained by phase-reversed chromatography. Positive control: galantamine 200 mmol $L^{-1}$, inhibitory activity against AChE: $92.0 \pm 4.5 \%$. Results represent means $\pm S D$ of three independent experiments. Concentration of each fraction: $5 \mathrm{mg} m L^{-1}$. Cb7-T: C. blankii LTW7 - trypsin. Cb7-TC: C. blankii LTW7-trypsin/chymotrypsin. Cb7-PC: C. blankii LTW7 - pepsin/chymotrypsin. Sc-PK: S. cerevisiaeproteinase K. Sc-PC: S. cerevisiae-pepsin/chymotrypsin. Pa6-PC: P. anomala LTW6-pepsin/chymotrypsin.

\subsection{Analysis of the Most Active Fractions by HPLC, HPAEC-PAD and MALDI-TOF Mass Spectrometry}

Fractions that exhibited the highest inhibition values against AChE, obtained by reversed phase liquid chromatography using Sep Pack C18 columns in tandem, were analyzed by high performance liquid chromatography, high performance anion exchange chromatography with Pulsed Amperometric Detection and MALDI-TOF mass spectrometry.

The fractions were as follows: extracts of mannoproteins of $C$. blankii LTW7 hydrolysed with trypsin, trypsin/chymotrypsin and pepsin/chymotrypsin eluted with $15 \%$ of ACN; extracts of $S$. cerevisiae DBFIQ L2 hydrolysed with proteinase $\mathrm{K}$ and pepsin/chymotrypsin, eluted with $15 \%$ of ACN; and extract of $P$. anomala LTW6 hydrolysed with pepsin/chymotrypsin, eluted with $2 \%$ of ACN. 


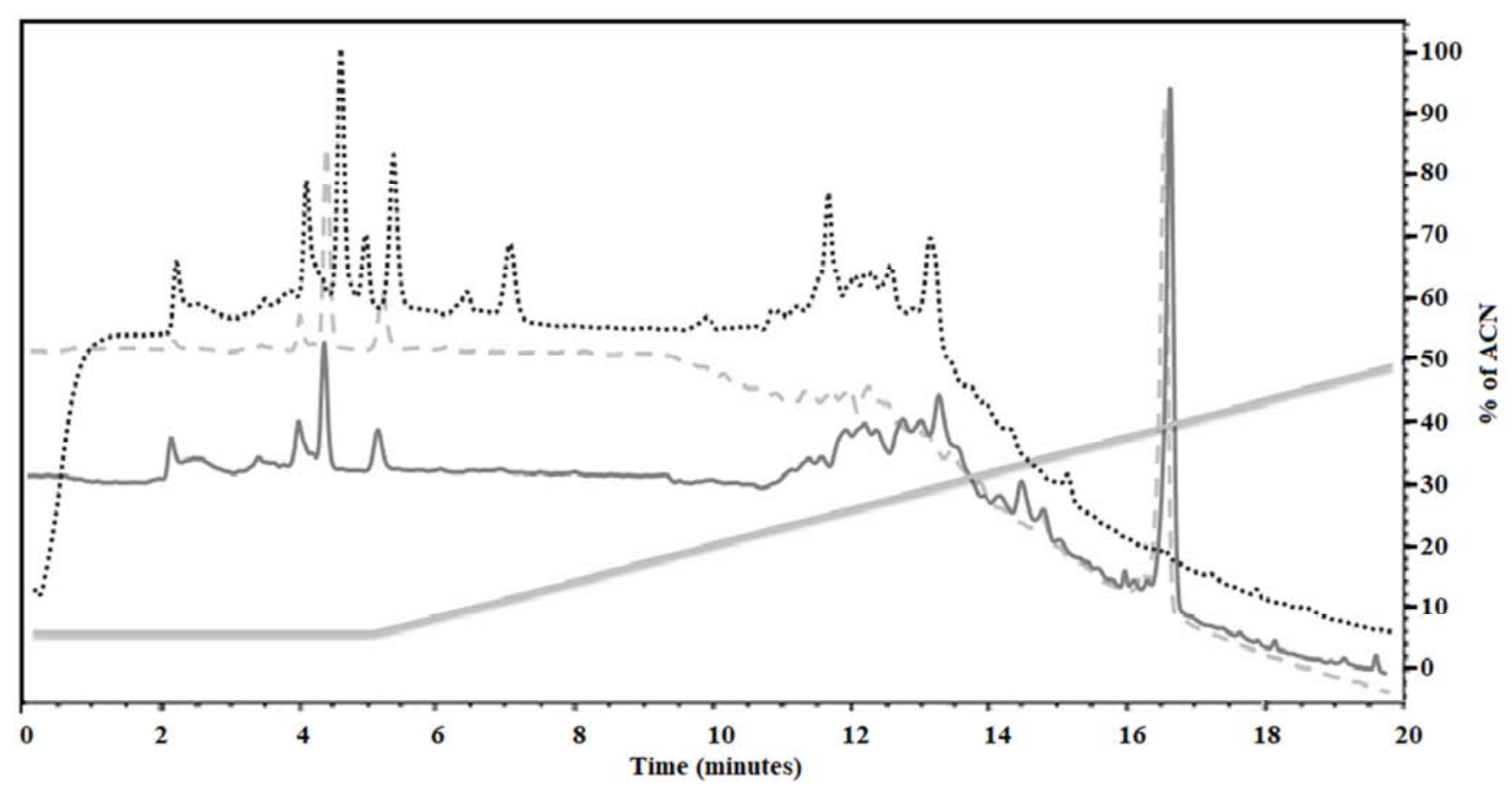

Figure 2. Reversed-phase HPLC chromatographic profiles of the fractions obtained using Sep Pack C18 cartridges, eluted with 15\% (v/v) ACN, of the extract of C. blankii LTW7 hydrolysed with trypsin (broken line), with trypsin/chymotrypsin (complete line) and pepsin/chymotrypsin (point). Column: Beckman C18, $5 \mu \mathrm{m}, 4.6 \mathrm{~mm} \times 260 \mathrm{~mm}$. Running time: $20 \mathrm{~min}$. Gradient $5-50 \%$ ACN. UV detection at $280 \mathrm{~nm}$.

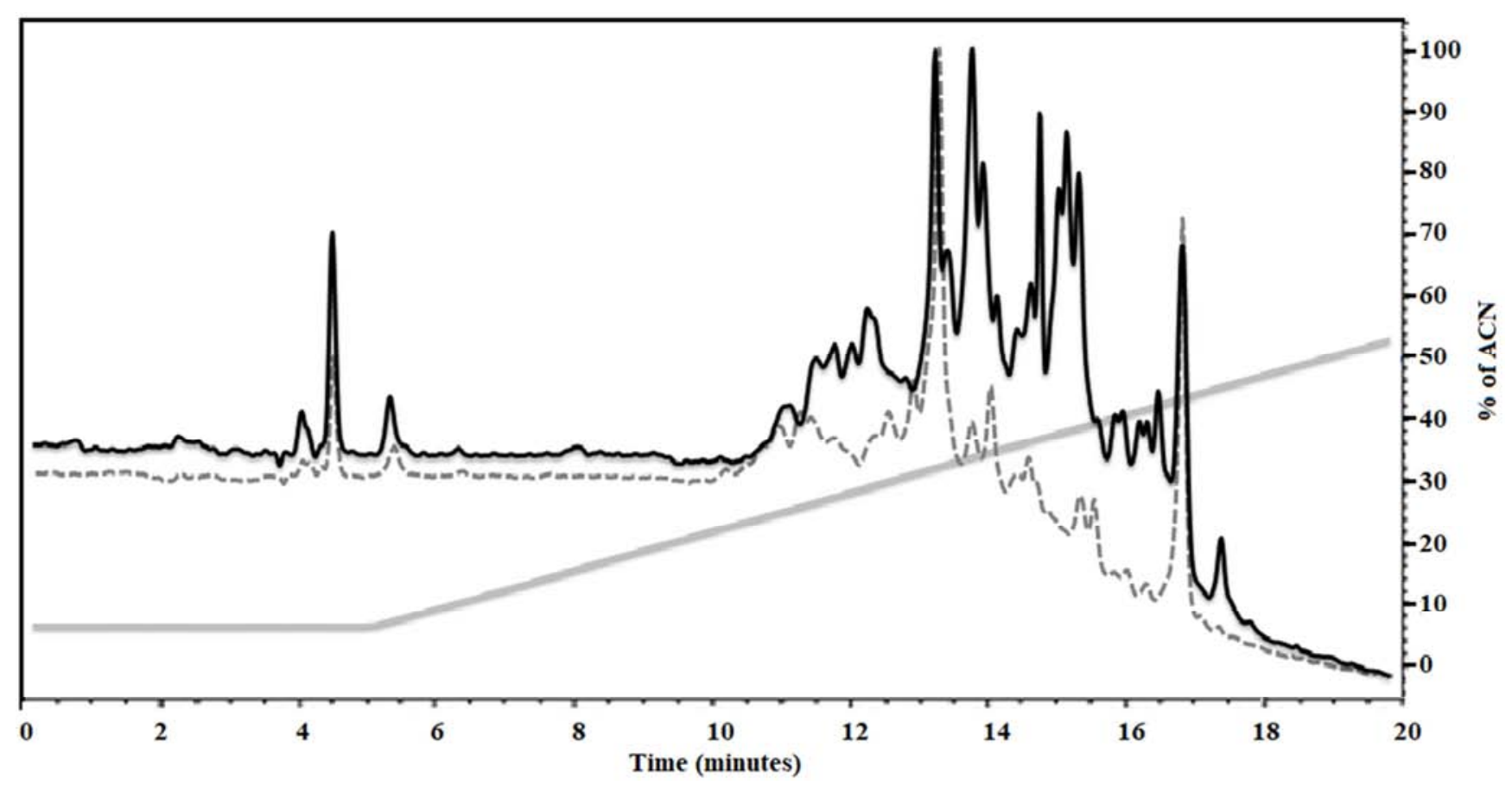

Figure 3. Reversed-phase HPLC chromatographic profiles of the fractions obtained using Sep Pack C18 cartridges, eluted with $15 \%$ (v/v) ACN, of the extract of S. cerevisiae L2 hydrolysed with proteinase K (broken line) and pepsin/chymotrypsin (complete line). Column: Beckman C18, $5 \mu \mathrm{m}, 4.6 \mathrm{~mm} \times 260 \mathrm{~mm}$. Running time: $20 \mathrm{~min}$. Gradient $5-50 \%$ ACN. UV detection at $280 \mathrm{~nm}$. 


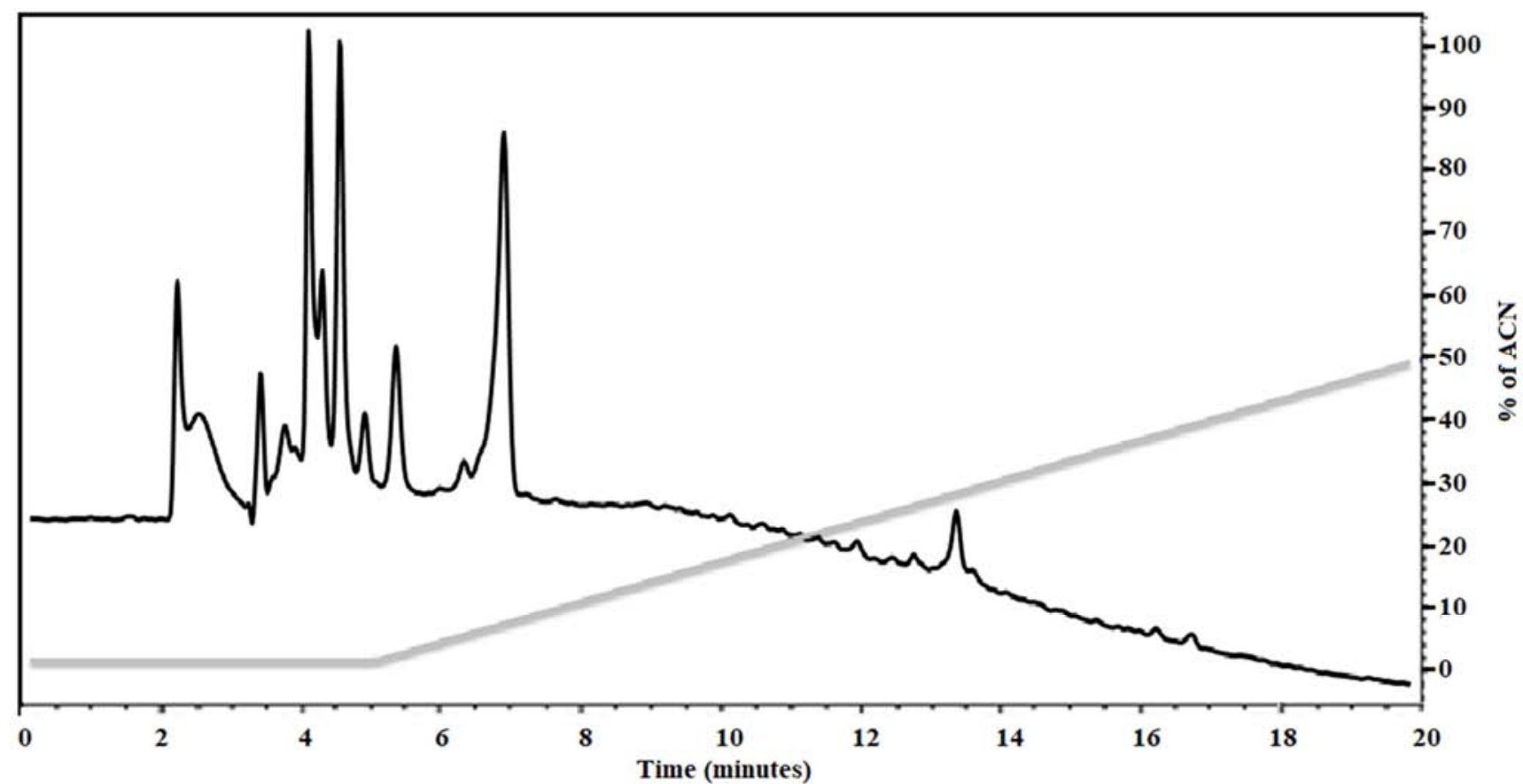

Figure 4. Reversed-phase HPLC chromatographic profile of the fraction obtained using Sep Pack C18 cartridges, eluted with 2\% (v/v) ACN, of the extract of P. anomala LTW6 hydrolysed with pepsin/chymotrypsin. Column: Beckman C18, $5 \mu \mathrm{m}, 4.6 \mathrm{~mm} \times 260 \mathrm{~mm}$. Running time: 20 min. Gradient 5 - 50\% ACN. UV detection at $280 \mathrm{~nm}$.

In Figures 2, 3 and 4 the chromatographic profiles obtained by HPLC of the 6 selected fractions can be observed. Peptides mainly hydrophilic, which were very little or slightly retained by the C18 column, were detected. In addition, it was found that the molecular weight of these fractions was between 700 and $4800 \mathrm{Da}$ (Data not shown).

Table 1. Determination of carbohydrate presence/absence.

\begin{tabular}{lllll}
\hline \multirow{2}{*}{ Yeast extracts } & Proteolytic enzyme & Carbohydrates & & Glucosamine \\
\cline { 3 - 5 } & trypsin & Mannose & Glucose & + \\
Candida blankii LTW7 & trypsin/chymotrypsin & +++ & ++ & ++ \\
& pepsin/chymotrypsin & +++ & ++ & + \\
Saccharomyces cerevisiae DBFIQ L2 & proteinase K & +++ & ++ & + \\
Pichia anomala LTW6 & pepsin/chymotrypsin & +++ & ++ & - \\
\hline
\end{tabular}

+++ Majority compounds; ++ Presence; + Very minority proportion; - Absence

Table 1 shows the results obtained by HPAEC-PAD, performed to verify the presence of different carbohydrates in the fractions that were active against the enzyme acetylcholinesterase.

Applying this methodology, the presence of mannose as majority compound, as well as some glucose, both present in all the analyzed extracts, and of a very minor proportion of glucosamine, was determined. The latter compound was detected only in four mannoprotein extracts: all three obtained from the strain C. blankii LTW7 and that from $S$. cerevisiae DBFIQ L2 hydrolysed with proteinase K.

Different authors found results consistent with those presented here when they determined the sugar residue content in the mannoproteins obtained after a thermal extraction. Mannose was the carbohydrate found to a greater extent $[22,26,27]$ and glucose was detected in smaller amount [26]. In contrast to the results of the present study, those researchers did not detect the presence of glucosamine.

\subsection{Chromatographic Separation of the Most Active Fractions Against AChE and Determination of the Inhibitory Activity}

After performing the chromatographic and spectroscopic analyses, the 6 mannoprotein most active fractions against AChE obtained by reversed-phase chromatography at low pressure were again separated. This separation was carried out by affinity chromatography using Concanavalin A, and two new fractions were obtained: a peptide fraction $(\mathrm{PF})$ and a glycopeptide fraction (GPF).

The inhibitory activity against AChE of each fraction was again determined. Results can be seen in the Figure 5 .

Results show that both peptidic and glycopectidic fractions showed inhibitory activity against AChE. It can be observed that GPF presented greater inhibition activity than PF against 
AChE, with activity values between 49.3 and $77.8 \%$. The GPF of C. blankii LTW7 hydrolysed with pepsin/chymotrypsin presented the highest percentage of inhibition. In contrast, PF inhibition values ranged from 14.1 to $46.7 \%$, the most active being the PF of $S$. cerevisiae DBFIQ L2 hydrolysed with pepsin/chymotrypsin. Likewise, all GPF presented higher values of inhibition than the corresponding fraction, while PF showed lower percentages of anti-AChE activity. Thus, these results allow us to conclude that the glycopeptides can act against AChE in greater proportion and with higher inhibition values.

However, two of the peptidic fractions, that of $C$. blankii LTW7 hydrolysed with trypsin/chymotrypsin and that of $S$. cerevisiae DBFIQ L2 hydrolysed with pepsin/chymotrypsin, also showed good activity results, with values of inhibition of 41.6 and $46.7 \%$, respectively. These results indicate that certain peptides originated by hydrolysis of the different mannoprotein extracts may also inhibit AChE to a large extent and should be taken into account as potential antiAChE agents.

To date, numerous studies have been carried out in much of the world to generate bioactive peptides by hydrolysis of dietary proteins. As a result, several enzymatic hydrolysates are currently applied to enhance the nutritional and functional properties of proteins. Besides, the use of enzymes with different hydrolysis mechanisms allows obtaining peptides with different bioactive properties [16]. Bioactive peptides have been isolated and characterized from various sources of dietary proteins, including milk and dairy products, eggs, fish, oysters, cereals (rice, wheat, barley and maize), soybeans, radish seeds, among others. Among the bioactive functions that have been identified, antihypertensive (angiotensin converting enzyme inhibitors), antioxidants, anticancer, immunomodulatory and antagonistic and opioid agonist properties can be mentioned [28].

However, it should be noted that previous research works on anti-acetylcholinesterase activity due to peptides or glycopeptides derived from yeast mannoproteins have not been found in the literature consulted. In addition, it is also noteworthy that very few reports have been found of protein hydrolysates or peptides isolated from different natural sources having inhibitory activity towards this enzyme. Also, the structural study of these hydrolysates or of their bioactive peptides is minimal or has not yet been performed.

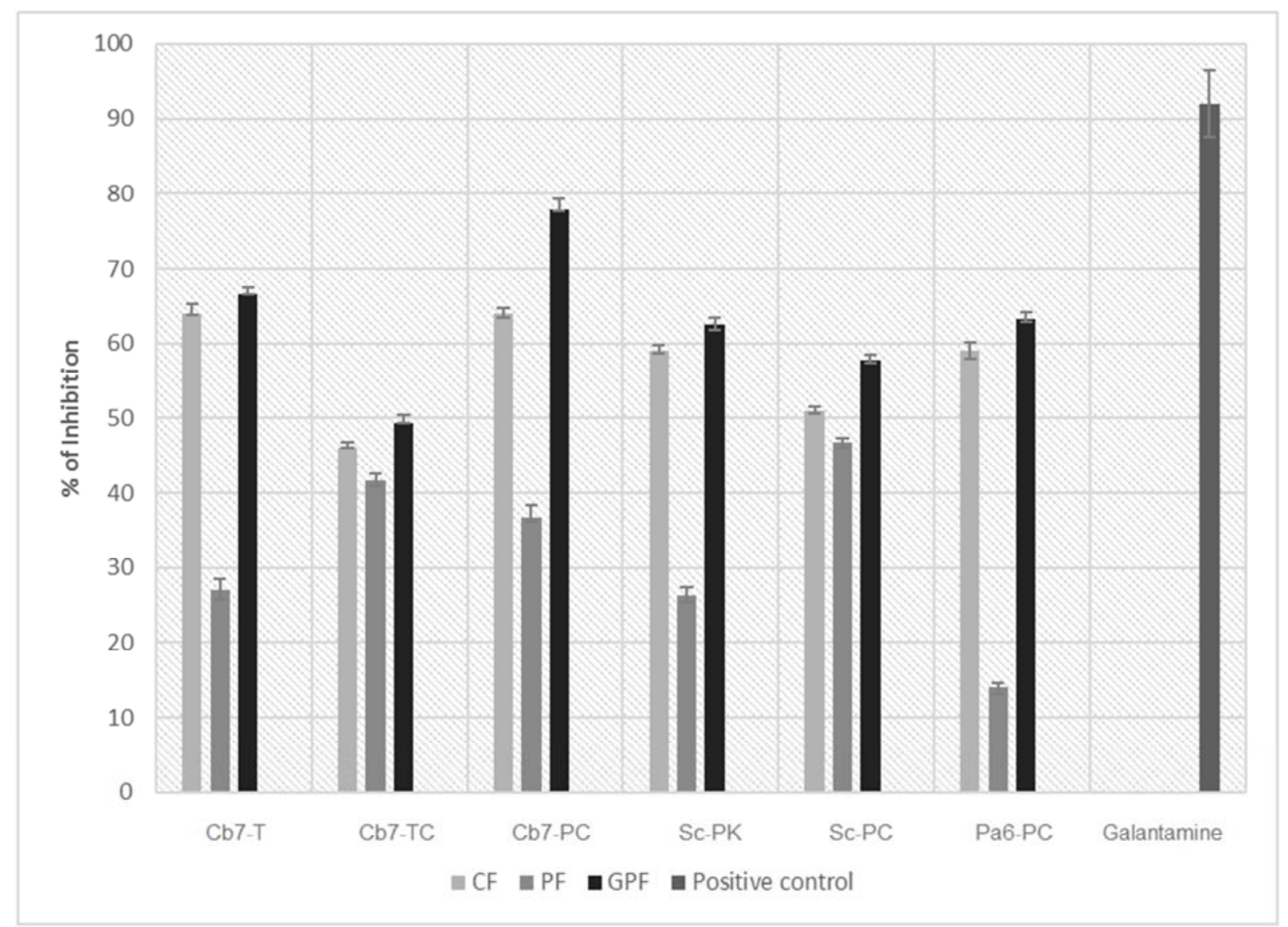

Figure 5. Inhibitory activity against AChE of the fractions obtained by phase-reversed chromatography. Positive control: galantamine 200 mmol $L^{-1}$, inhibitory activity against AChE: $89.5 \pm 0.7 \%$. Results represent means $\pm S D$ of three independent experiments. Concentration of each fraction: 5 $m g$ mL $L^{-1}$. Cb7-T: C. blankii LTW7 - trypsin. Cb7-TC: C. blankii LTW7 - trypsin/chymotrypsin. Cb7-PC: C. blankii LTW7 - pepsin/chymotrypsin. Sc-PK: S. cerevisiae - proteinase K. Sc-PC: S. cerevisiae - pepsin/chymotrypsin. Pa6-PC: P. anomala LTW6-pepsin/chymotrypsin. CF: complete fraction. PF: peptide fraction. GPF: glycopeptide fraction.

Therefore, due to the scarce information in literature, comparison of the inhibitory activity against AChE of the 
different peptide or glycopeptide fractions of the mannoprotein hydrolysates obtained in this study is a difficult task.

One of such peptides with anti-AChE activity that has been found and characterized is the cationic peptide Snakin$\mathrm{Z}$, isolated from fruits of Zizyphus jujuba, a medicinal plant [29]. This peptide has a molecular mass of $3318.82 \mathrm{Da}$ and the following sequence: CARLNCVPKGTSGNTETCPCYASLHSCRKYG. It is a basic peptide with a net charge of +4 . In another study [30], the authors determined that a glycoprotein isolated from Undaria pinnatifida, a macroalgae, possesses AChE inhibitory activity. This glycoprotein has a molecular weight of about $10 \mathrm{kDa}$. In addition, [31] isolated two peptidepolysaccharide complexes called CPSP-F1 and CPSP-F2, which exhibited good anti-AChE activity. They were obtained from the fungus Cordyceps militaris. Both peptidepolysaccharide complexes are composed primarily of mannose, galactose and arabinose. The polymers are composed of acidic and non-polar amino acids, such as glutamic acid and proline. In addition, the amino acids alanine, glycine and leucine were detected to a greater extent in CPSP-F1, whereas lysine and methionine were detected in CPSP-F2.

Two other peptides exhibiting anti-AChE activity are Fasciculin 1 and Fasciculin 2, isolated from the venom of the green mamba snake, Dendroaspis angusticeps. Both Fasciculins have 61 amino acid residues, 4 disulfide bonds and a net charge of +4 . The molecular weight is $6765 \mathrm{Da}$ for Fasciculin 1 and 6735 Da for Fasciculin 2 [32, 33].

The chromatographic and spectrometric analysis of the 6 most active fractions of mannoprotein hydrolysates investigated in the present work showed the presence of peptides or glycopeptides with molecular weights ranging from 700 to $4800 \mathrm{Da}$, mainly hydrophilic. The presence of three sugar residues: mannose, glucose and glucosamine, was also found. Anti-AChE activity was mainly focused on glycopeptide fractions, although two of the six peptide fractions showed good inhibitory activity against AChE.

\section{Conclusion}

Given the complexity of $\mathrm{AD}$, new therapeutic approaches to treat this disease and other neurological disorders include finding bioactive compounds that can act on multiple targets.

The results obtained in this research work after fractionation and subsequent characterization of the different hydrolysed extracts of mannoproteins corroborated the presence of both peptides and glycopeptides in the different fractions active against $\mathrm{AChE}$, the latter having the highest inhibitory activity. Mannose, glucose and glucosamine were the sugar residues detected in these fractions.

This study demonstrates that the peptides/glycopeptides released by enzymatic hydrolysis of yeast mannoprotein extracts, which were active against acetylcholinesterase enzyme, can be potential components of functional or nutraceutical foods. In addition, it is important to note that in the literature consulted, no previous research on this activity has been found, related to peptides obtained from yeast mannoproteins. Therefore, and to our knowledge, this would be one of the first scientific works dedicated to this specific topic, and may be considered a promising aspect of food manufacture, with potential implications in the formulation of new therapeutic agents and functional foods.

\section{Acknowledgements}

This work was partially sponsored by grants from the Program 'Curso de Acción para la Investigación y el Desarrollo - C. A. I.+D. 2016' (Secretaría de Ciencia y Técnica, Universidad Nacional del Litoral, Argentina).

\section{References}

[1] Sung, W. S.; Park, Y.; Choi, C. H.; Hahm, K. S. and Lee D. G. (2007) Mode of antibacterial action of a signal peptide, Pep27 from Streptococcus pneumoniae. Biochemical Biophysical Research Communications, 363 (3): 806-810.

[2] Duval, E.; Zatylny, C.; Laurencin, M.; Baudy-Floc'h, M. and Henry, J. (2009) KKKKPLFGLFFGLF: a cationic peptide designed to exert antibacterial activity. Peptides, 30 (9): 16081612 .

[3] Lin, P. and Ng, T. B. (2008) A novel and exploitable antifungal peptide from kale (Brassica alboglabra) seeds. Peptides, 29 (10): 1664-1671.

[4] Pan, Y.; Lee, A.; Wan, J.; Coventry, M. J.; Michalski, W. P.; Shiell, P. and Roginski, H. (2006) Antiviral properties of milk proteins and peptides. International Dairy Journal, 16 (11): 1252-1261.

[5] Rockwood, K.; Bouchard, R. W.; Camicioli, R. and Le'ger, G. (2007) Toward a revision of criteria for the dementias. Alzheimers Dement, 3 (4): 428-440.

[6] Grinberg, L. T. and Heinsen, H. (2010) Toward a pathological definition of vascular dementia. Journal of Neurological Sciences, 299 (1-2): 136-138.

[7] Caroli, A. and Frisoni, G. B. (2010) The dynamics of Alzheimer's disease biomarkers in the Alzheimer's disease neuroimaging initiative cohort. Neurobiology of Aging, 31 (8): 1263-1274.

[8] Swerdlow, R. H. (2011) Brain aging, Alzheimer's disease, and mitochondria. Biochimicaet Biophysica Acta, 1812 (12): 1630-1639.

[9] Kettl, P. (2007) Helping families with end-of-life care in Alzheimer's disease. Journal Clinical Psychiatry, 68 (3): 428429.

[10] Singh, A. P. (2003) The role of natural products in pharmacotherapy of Alzheimer disease. Ethnobotanical Leaflets, 7: 1-5.

[11] Keane, S. and Ryan, M. F. (1999) Purification, characterization, and inhibition by monoterpenes of acetylcholinesterase from the wax moth, Galleria Mellonella. Insect Biochemistry and Molecular Biology, 29: 1097-1104. 
[12] Filho, J.; Medeiros, K.; Diniz, M.; Batista, L.; Athayde-Filho, P. and Silva, M. (2006) Natural products inhibitors of the enzyme acetylcholinesterase. Revista Brasileira de Pharmacognosia, 16: 258-285.

[13] Pulok, K. M.; Venkatesan, K.; Mainak, M. and Houghton, P. J. (2007) Acetylcholinesterase inhibitors from plants. Phytomedicine, 14: 289-300.

[14] Kantor, D. (2007) Enfermedad de Alzheimer. Review provided by VeriMed Healthcare NetYork. Medline plus enciclopediamédica.

http://www.nlm.nih.gov/medlineplus/spanish/ency/article/000 760.htm

[15] Murray, A. P.; Faraoni, M. B.; Castro, M. J.; Alza, N. P. and Cavallaro, V. (2013) Natural AChE inhibitors from plants and their contribution to Alzheimer's disease therapy. Current Neuropharmacology, 11: 388-413.

[16] Ahn, C. B.; Lee, K. H. and Je, J. Y. (2010) Enzymatic production of bioactive protein hydrolysates from tuna liver: effect of enzymes and molecular weight on bioactivity. International Journal of Food Science and Technology, 45: $562-568$.

[17] Patocka, J. (2012) Natural cholinesterase inhibitors from mushrooms. Military Medical Science Letters, 81 (1): 40-44.

[18] Custódio, L.; Justo, T.; Silvestre, L.; Barradas, A.; Duarte, C. V.; Pereira, H.; Barreira, L.; Rauter, A. P.; Alberício, F. and Varela, J. (2012) Microalgae of different phyla display antioxidant, metal chelating and acetylcholinesterase inhibitory activities. Food Chemistry, 131: 134-140.

[19] Núñez, Y. P .; Carrascosa, A. V.; González, R.; Polo, M. C. and Martínez Rodríguez, A. J. (2006) Isolation and characterization of a thermally extracted yeast cell wall fraction potentially useful for improving the foaming properties of sparkling wines. Journal of Agriculture and Food Chemistry, 54: 7898-7903.

[20] Spontón, P. G.; Spinelli, R.; Drago, S. R.; Tonarelli, G. G. and Simonetta, A. C. (2016) Acetylcholinesterase-inhibitor hydrolysates obtained from 'in vitro' enzymatic hydrolysis of mannoproteins extracted from different strains of yeasts. International Journal of Food Science and Technology, 51, 300-308.

[21] Peat, S.; Whelan, W. J. and Edwards, T. E. (1961). Polysaccharides of baker's yeast. Part IV. Mannan. Journal of Chemical Society, (London): 28-35.

[22] Cameron, D.; Cooper, D. and Neufeld R. (1988) The mannoprotein of Saccharomyces cerevisiae is an effective bioemulsifier. Applied and Environmental Microbiology, 54: 1420-1425.
[23] Ellman, G. L.; Courtney, K. D.; Andres, V. Jr. and FeatherStone, R. M. (1961) A new and rapid colorimetric determination of acetylcholinesterase activity. Biochemical Pharmacology, 7: 88-95.

[24] López, S., Bastida, J., Viladomat, F. and Codina, C. (2002). Acetylcholinesterase inhibitory activity of some Amaryllidaceae alkaloids and Narcissus extracts. Life Sciences, 71, 2521-2529.

[25] Hardy, M. R. and Townsend R. R. (1994) High-pH anionexchange chromatography of glycoprotein-derived carbohydrates. Methods Enzymology, 230: 208-225.

[26] Gañan, M.; Carrascosa, A. V.; de Pascual-Teresa, S. andMartínez-Rodríguez, A. J. (2009) Inhibition by yeastderived mannoproteins of adherence to and invasion of Caco2 cells by Campylobacter jejuni. Journal of Food Protection, 72: $55-59$.

[27] Dikit, P. S. M.; Musikasang, H. and Kittikun A. H. (2010) Emulsifier properties of the mannoprotein extract from yeast isolated from sugar palm wine. ScienceAsia, 36: 312-318.

[28] Wang, W. and de Mejia, E. G. (2005). A new frontier in soy bioactive peptides that may prevent age-related diseases. Comprehensive Reviews in Food Science and Food Safety, 4: 63-78.

[29] Zare-Zardini, H.; Tolueinia, B.; Hashemi, A.; Ebrahimi, L. and Fesahat, F. (2013). Antioxidant and cholinesterase inhibitory activity of a new peptide from Ziziphus jujuba fruits. American Journal of Alzheimer's Disease and Other Dementias, 28 (7): 702-709.

[30] Rafiquzzaman, S. M.; Kim, E. Y.; Lee, J. M.; MdMohibbullah; MdBadrulAlam; Moon, I. S.; Kim, J. M. and Kong, I. S. (2015) Anti-Alzheimers and antiinflammatory activities of a glycoprotein purified from the edible brown alga Undariapinnatifida. Food Research International, 77: 18124.

[31] Tsai, C. H.; Yen, Y. H. and Yang, J. P. W. (2015) Finding of polysaccharide-peptide complexes in Cordyceps militaris and evaluation of its acetylcholinesterase inhibition activity. Journal of Food and Drug Analysis, 23: 63-70.

[32] Karlsson, E.; Mbugua, P. M. and Rodriguez-Itthurralde, D. (1984) Fasciculins, anticholinesterase toxins from the venom of the green mamba Dendroaspis angusticeps. Journal of Physiology, 79: 232-240.

[33] Kafurke, U.; Erijman, A.; Aizner, Y.; Shifman, J. M. and Eichlera, J. (2015) Synthetic peptides mimicking the binding site of human acetylcholinesterase for its inhibitor fasciculin 2. Journal of Peptide Sciences, 21 (9): 723-730. 